\title{
Design of stem separator tool with Cyclea Barbata (Cincau) plant leaves to increase business productivity of Sunter Jaya Residents of Jakarta Utara
}

\author{
Ahmad Yunus ${ }^{1 *}$, Ika Kurniaty ${ }^{1}$, Fatma Sari ${ }^{1}$, Meri Prasetyawati ${ }^{1}$, Prian Gagani Chamdareno ${ }^{1}$, \\ Tri Kurnianto ${ }^{1}$ \\ ${ }^{1}$ Faculty of Engineering, Universitas Muhammadiyah Jakarta, Jakarta, Indonesia \\ *Email: ahmad.yunus@ftumj.ac.id
}

\begin{abstract}
Cincau (Cyclea barbata) is a plant whose leaves can be squeezed thick for the contents of a drink. This plant is a species of the cyclea genus. Green grass jelly leaves are found in various places in Indonesia, from traditional markets to modern shopping centers. This plant is known as camcao (Javanese), camcauh (Sundanese), juju, kepleng, krotok, tarawalu, tahulu (Malay). There are several types of grass jelly known today, namely green grass jelly, black grass jelly, and oil grass jelly. Indonesian people are fond of green grass jelly because the physical nature of green grass jelly leaves (Cyclea barbata) is thin and limp so that it is easier to form into gelatin or into gelatin. So far, research that examines quality improvement in the processing process has not been given much attention, because many think that the process currently carried out meets the standards. For this reason, through this research, efforts were made to improve the quality of Cyclea barbata leaves through the initial stages of the Cyclea barbata leaf processing process. The stalks and leaves of the henna must be separated from the beginning of the processing process before being processed further, so that the pure processed material comes from Cyclea barbata leaves which produce the best Cyclea barbata leaf powder, so that it is expected to produce quality Cyclea barbata leaf products. For that we need a separator for the leaves and stems of the Cyclea barbata plant. This research is needed to produce a design for separating the stem and leaves of the Cyclea barbata plant. The design of this tool needs to refer to the physical characteristics of the leaves and stems of the Cyclea barbata plant, so that power requirements are reduced and operational costs decrease.
\end{abstract}

Keyword: Cylea barbata, Design Tool, Drive Motor

\begin{abstract}
Abstrak
Cincau (Cyclea barbata) adalah tumbuhan yang daunnya dapat diperas menjadi kental untuk isi minuman. Tumbuhan ini merupakan spesies dari genus cyclea Daun cincau hijau banyak ditemui di berbagai tempat di Indonesia, dari pasar tradisional hingga di pusat perbelanjaan modern. Tanaman ini dikenal dengan nama camcao (Jawa), camcauh (Sunda), juju, kepleng, krotok, tarawalu, tahulu (Melayu). Terdapat beberapa jenis cincau yang dikenal saat ini yaitu cincau hijau, cincau hitam, dan cincau minyak. Masyarakat Indonesia menggemari jenis cincau hijau karena fisik daun cincau hijau (Cyclea barbata) yang tipis dan lemas sehingga lebih mudah dibentuk menjadi gelatin ataupun menjadi agar- agar.Sejauh ini penelitian yang mengkaji peningkatan mutu dalam proses pengolahan masih kurang diperhatikan, karena banyak yang beranggapan bahwa proses yang dilakukan saat ini sudah memenuhi standar. Untuk itu melalui penelitian ini dilakukan upaya peningkatan mutu daun Cyclea barbata melalui tahap awal proses pengolahan daun Cyclea barbata. Tangkai dan daun inai harus dipisahkan sejak awal proses pengolahan sebelum diolah lebih lanjut, sehingga bahan yang diolah murni berasal dari daun Cyclea barbata yang menghasilkan bubuk daun Cyclea barbata terbaik, sehingga diharapkan dapat menghasilkan produk daun Cyclea barbata berkualitas. Untuk itu diperlukan alat pemisah daun dan batang tanaman Cyclea barbata. Penelitian ini diperlukan untuk menghasilkan rancang bangun alat pemisah batang dan daun tanaman Cyclea barbata. Rancang bangun alat ini perlu mengacu pada karakteristik fisik dari daun dan batang tanaman Cyclea barbata.Sehingga, kebutuhan daya berkurang dan biaya operasional menurun.
\end{abstract}

Kata Kunci : Cylea barbata, Rancang Bangun alat, Motor Penggerak 


\section{PENDAhuluan}

Cincau dapat dibuat sebagai minuman kessehatan pagi penderita kanker. Telah dilakukan penelitian tentang pengaruh ekstrak daun cincau hijau terhadap aktivitas enzim antioksidan superoksidase dismutase dan katalase pada mencit bertumor mammary. Makhluk hidup yang mengalami gangguan kesehatan kanker dapat mengalami stress oksidatif dan gangguan system imum pada waktu yang bersamaan yang dapat memperburuk kondisi tubuh penderita. Untuk memperbaiki kondisi tubuhnya, penderita kanker memerlukan sumber makanan dan minuman sehat dan bergizi seperti minuman cincau

Warga RT 007 RW 01 Sunter Jaya merupakan salah satu daerah yang membudidayakan tanaan cincau. Program Kemitraan Masyarakat (PKM) ini akan diarahkan pada usaha/bisnis produksi makanan komersial dari cincau sebagai produk khas dari warga RT 007 RW 01 Sunter Jaya. Program akan bermitra dengan anggota masyarakat di RT 007 RW 01 Sunter Jaya sebagai calon pengusaha yang memiliki kemauan kuat untuk maju. Dalam pelaksanaan dibagi menjadi tiga kelompok, yang masing-masing kelompok terdiri dari tiga orang. Hal ini bertujuan untuk mempermudah pelaksanaan kegiatan usaha. Ketiga kelompok tersebut akan mengembangkan usaha pembuatan produk makanan dari daun cincau, dimana kelompok I akan membuat es daun cincau, kelompok II akan membuat keripik daun cincau, dan kelompok III akan membuat nastar berbahan tepung daun cincau.

Pihak mitra maupun pengusul program sangat yakin terhadap prospek usaha makanan dari daun cincau ini. Pertama, bila dilihat dari aspek pemasaran produk, bisnis ini memiliki prospek pemasaran yang sangat menjanjikan. Sampai saat ini belum ada produk lokal yang dapat dijadikan sebagai makanan khas dari masyarakat di RT 007 RW 01 Sunter Jaya berbahan daun cincau. Berdasarkan hasil survei yang dilakukan oleh pengusul, toko-toko atau warung-warung yang ada belum ada yang menawarkan produk makanan lokal tersebut. Selain itu di kecamatan tersebut terdapat pasar tradisional yang cukup penting bagi aktivitas jual beli masyarakat. Pasar tersebut dapat dijadikan salah satu target tempat penjualan produk makanan yang akan dihasilkan oleh mitra. Lebih lanjut, tidak menutup kemungkinan untuk mempromosikan dan memasarkan produk pada pasar-pasar tradisional maupun pasar swalayan yang ada di Kabupaten dan Kota.

Kedua, bila dilihat dari ketersediaan bahan baku, hasil panen cincau di masyarakat di RT 007 RW 01 Sunter Jaya tergolong paling tinggi bila dibandingkan dengan daerah-daerah lain di Jakarta Utara, sehingga dapat menjadi sentra produksi cincau di Jakarta. . Bila dilihat keadaan produksi daun cincau dari pihak mitra, setiap kepala keluarga $(\mathrm{KK})$ dari anggota mitra ini rata-rata memiliki lahan budidaya sebanyak 3-4 petak. Pemanenan umumnya dilakukan setiap 30 hari. Jadi ketersediaan bahan baku sangat menunjang pengembangan usaha produksi makanan dari daun cincau ini.

Ketiga, bila dilihat dari ketersediaan waktu untuk usaha, setiap anggota dari mitra kegiatan ini memiliki waktu yang cukup luang untuk menggeluti usaha yang ditawarkan. Pihak mitra cukup banyak memiliki waktu luang diantara musim tanam dan musim panen yang berselang sekitar 30 hari. Bila dilihat dari aspek sumber daya manusia, anggota mitra sebenarnya telah memiliki kepengtahuan dasar untuk membuat produk makanan dari daun cincau. 

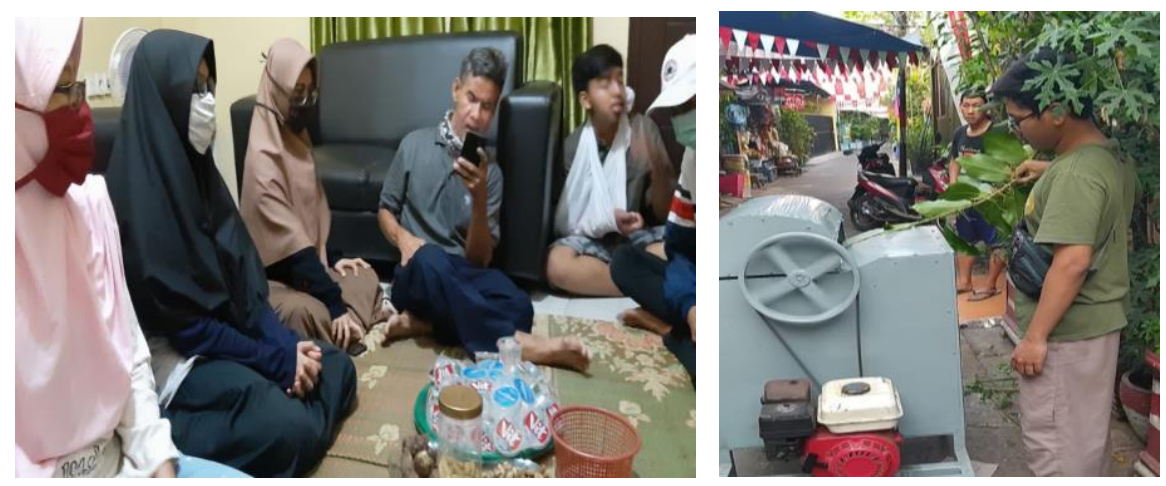

Gambar 1.1. Warga RT 007 berdiskusi terkait pembuatan produk
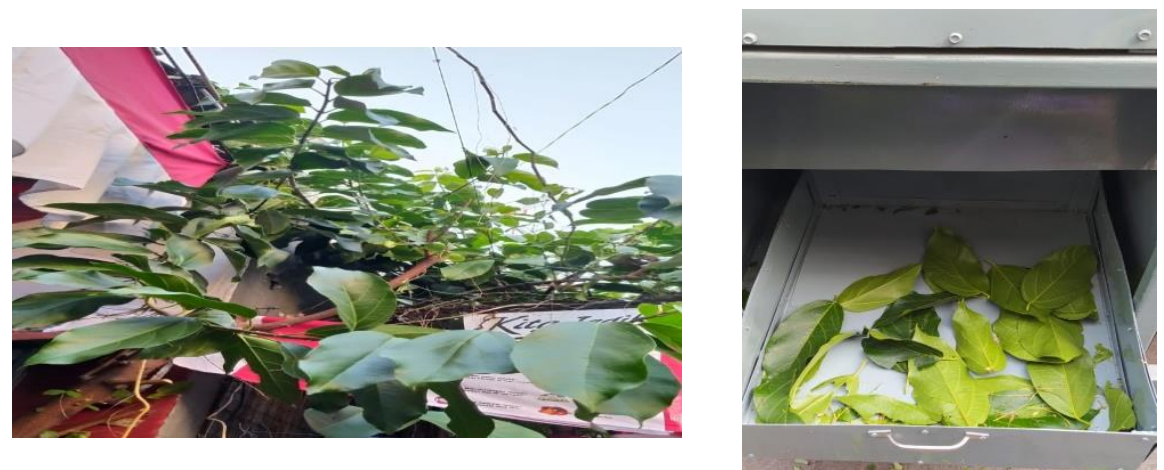

Gambar 1.2. Daun Cincau yang di tanam Warga RT 007

Hasil wawancara dengan mitra menunjukkan permasalahan utama yang menghambat mereka mengembangkan usaha dari daun cincau ini adalah terkait produksi dan pemasaran produk. Permasalahan produksi yang dihadapi terkait minimnya modal terutama untuk membeli peralatan untuk produksi dan mengemas hasil produksi menjadi lebih menarik. Untuk menghasilkan produk permen es daun cincau, keripik daun cincau, dan nastar daun cincau yang baik perlu ditunjang oleh peralatan yang baik dan modern dalam rangka efisiensi dan efektifitas proses produksi dan pengemasannya. Peralatan utama yang diperlukan untuk produksi ketiga makanan tersebut antara lain: alat perontok daun cincau, ayakan, baskom, cetakan nastar, Loyang, mangkuk kecil, mixer, oven, sarung tangan plastik, dan sendok.

Permasalahan kedua terkait pemasaran produk. Mitra belum berani memulai usaha karena sudah merasa ketakutan bahwa produk yang akan dihasilkan tidak laku di pasaran. Apalagi modal yang dimiliki sangat kecil, mereka tidak berani mengambil resiko kalau terjadi kerugian. Harga daun cincau di hingga saat ini sering berfluktuasi dari Rp. 1.000,- hingga Rp.2.000,- untuk tiap 100 gram. Terkait pengemasan produk, mitra juga belum paham betul mengenai teknik pengemasan produk yang baik dan menarik yang dapat memberikan ciri khas bagi produk yang dihasilkan. Selain itu, menurut keterangan mitra, mereka sebenarnya sempat mencoba membuat produk makanan dari daun cincau. Namun mereka kurang yakin dengan kualitas produk yang dihasilkan, khususnya terkait cita rasa dan penampilan produk. Hal ini disebabkan dan mereka mencoba sendiri menggunakan peralatan produksi seadanya.

Bila dilihat dari aspek manajemen, mitra belum paham bagaimana mengelola suatu usaha mulai dari penyediaan bahan baku, proses produksi, promosi dan pemasaran. Mitra juga belum tahu bagaimana pengaturan keuangan suatu unit usaha untuk menjamin keberlangsungan serta perkembangan usaha tersebut. Mereka sebenarnya telah memiliki kemampuan manajemen meskipun masih pada level paling dasar. Sebagai contoh, mitra sudah mampu mengatur penyediaan bibit, proses penanaman dan pemanenan, serta penanganan pasca panen yang menjamin keberlangsungan budidaya tanaman cincau yang mereka geluti hingga saat ini. 
Kemampuan ini tentu diperoleh secara turun-temurun, karena usaha budidaya tanaman cincau ini umumnya diteruskan pada keturunan berikutnya. Akan tetapi, mereka belum mampu melakukan manajemen yang efektif dan efisien dalam kaitannya dengan pengembangan suatu usaha. Demikian juga, mitra belum memiliki kemampuan dan skil yang memadai untuk merintis dan mengelola suatu usaha baru.

Berdasarkan permasalahan yang dihadapi, pihak mitra sangat mengharapkan adanya bantuan modal serta pelatihan dan pendampingan secara kontinyu yang akan mengawal mereka sehingga merekadapat mengembangkan unit usaha produk makanan dari daun cincau ini secara mandiri.

\section{METODE PELAKSANAAN}

Untuk merealisasikan solusi pemecahan masalah yang ditawarkan maka, kegiatan Program Kemitraan Masyarakat (PKM) ini akan dilakukan melalui lima tahapan kegiatan sebagai berikut :

1. Tahap I (Penyuluhan/sosialisasi)

Pada tahap awal mitra akan diberikan pengetahuan/wawasan mengenai prospek usaha yang akan mereka kembangkan, termasuk bagaimana teknik produksi, pemasaran maupun manajemen usahanya. Penyuluhan akan dilaksanakan dengan metode ceramah dan diskusi. Kegiatan ini bertujuan untuk lebih meyakinkan dan memantapkan pengetahuan, wawasan serta semangat mitra untuk memulai usaha baru.

2. Tahap II (Pelatihan Teknik Produksi dan Pengemasan Produk)

Pada tahap ini mitra akan dilatih untuk membuat produk makanan dari daun cincau (membuat es daun cincau, keripik daun cincau, dan nastar berbahan tepung daun cincau). Selama pelatihan akan dilakukan kegiatan pembimbingan dan konsultasi sehingga mitra benar-benar mampu dan terampil membuat produk yang berkualitas. Selanjutnya mitra diberikan pelatihan mengenai cara pengemasan produk yang menarik dan memiliki ciri khas tersendiri.

3. Tahap III (Pelatihan Teknik Promosi dan Pemasaran Produk)

Pada tahap ini mitra akan dilatih dan dibimbing secara kontinyu mengenai cara-cara mempromosikan dan memasarkan produk yang dihasilkan. Kegiatan ini dikawal hingga kedua mitra berhasil berhasil memasarkan produknya yang dapat menjamin keberlangsungan usahanya.

4. Tahap IV (Penyuluhan Tentang Manajemen Usaha)

Pada tahap ini mitra akan dibekali dengan kiat-kiat mengelola suatu bisnis/usaha. Kegiatan dilakukan melalui ceramah dan diskusi hingga pihak mitra benar-benar menguasai konsep-konsep pengelolaan usaha yang baik untuk menjamin eksistensi dan kemajuan usaha yang akan mereka geluti.

5. Tahap V (Monitoring dan Pendampingan)

Pihak pengusul kegiatan akan melakukan monitoring dan pendampingan secara berkala untuk memastikan keberlanjutan usaha yang akan dikembangkan oleh kedua mitra. Pada tahap ini, pihak pengusul juga akan melakukan analisis terhadap kemungkinan permasalahan yang muncul dari pihak mitra selama menjalani usaha serta mengupayakan solusinya.

Keberhasilan kegiatan PKM ini tentu saja sangat tergantung pada partisipasi aktif dari pihak mitra. Partisipasi pihak mitra yang diharapkan dalam kegiatan ini adalah sebagai berikut:

1) Menyediakan tempat khusus untuk usaha

2) Menyediakan bahan baku daun cincau

3) Mengikuti seluruh kegiatan dari sosialisasi, penyuluhan/pelatihan, serta kegiatan monitoring dan pembimbingan

4) Berkomitmen tinggi untuk meneruskan dan mengembangkan usaha yang akan dilatihkan. 
Untuk merealisasikan tujuan kegiatan PKM ini, diperlukan tim pelaksana yang memiliki kualifikasi yang memadai sesuai dengan kepakaran yang diperlukan dalam keberhasilan pelaksanaan kegiatan.

\section{HASIL DAN PEMBAHASAN}

Berdasarkan hasil kesepakatan dengan pihak mitra, permasalahan utama yang akan dicarikan solusi melalui kegiatan/program ini meliputi dua aspek, yaitu aspek produksi dan manajemen.

Permasalahan terkait aspek produksi meliputi:

1) Mitra tidak memiliki peralatan yang memadai untuk menunjang proses produksi yang efektif dan efisien akibat minimnya modal yang dimiliki. Permasalahan ini mendapatkan prioritas untuk memberikan kemudahan kepada mitra dalam melakukan proses produksi.

2) Mitra belum terampil membuat produk makanan yang berkualitas dari daun cincau. Mereka belum terampil dan kurang yakin dengan kualitas produk yang mereka hasilkan terutama dalam hal cita rasa dan penampilannya. Hal ini disebabkan kurangnya semangat dan keuletan mitra untuk secara kontinyu mencoba dan berlatih. Permasalahan ini mendapat prioritas untuk memberikan bekal kemampuan, keterampilan dan keyakinan kepada mitra bahwa mereka mampu menghasilkan produk makanan dari bahan daun cincau yang berkualitas.

3) Mitra belum mampu mengemas hasil produksi secara menarik. Pihak mitra belum mengetahui teknik pengemasan produk yang menarik yang mampu memberikan ciri khas yang dapat meyakinkan calon pembeli. Permasalahan ini memperoleh perhatian karena dapat mempengaruhi keberhasilan pemasaran produk.

Permasalahan mitra terkait aspek manajemen yang akan dicarikan solusi pemecahannya meliputi:

1) Mitra belum paham dan terampil dalam mengelola suatu bisnis/usaha yang akan digeluti. Mitra masih sangat awam dengan manajemen suatu usaha yang efektif dan efisien. Permasalahan ini menjadi prioritas untuk menjamin keberlanjutan dan kemajuan usaha yang akan digeluti oleh kedua mitra.

2) Mitra belum paham dan terampil dalam mengelola teknik promosi dan pemasaran produk yang akan dihasilkan. Mitra masih belum mengetahui bagaimana mempromosikan dan memasarkan produk secara baik. Permasalahan ini menjadi prioritas karena pemasaran merupakan salah satu kunci keberhasilan suatu usaha.

Solusi yang ditawarkan untuk menyelesaikan permasalahan yang dihadapi mitra harus sesuai dengan prioritas permasalahan yang dihadapi. Berdasarkan analisa situasi permasalahan sebelumnya, solusi yang ditawarkan yaitu melakukan kegiatan :

1) Pemberian bantuan peralatan produksi dan pengemasan produk hasil yang diharapkan :

Mitra memiliki alat-alat produksi dan alat-alat pengemas produk yang memadai.

2) Pelatihan produksi makanan dari daun pandan (es daun cincau, keripik daun cincau, nastar berbahan tepung daun cincau)

Hasil yang diharapkan :

a. Es daun cincau segar yang murni dan sehat dari daun cincauaseli.

b. Keripik daun cincau yang renyah, gurih dan bercita rasa khas daun cincau.

c. Nastar berbahan tepung daun cincau yang sehat.

d. Mitra mampu dan terampil membuat produk makanan khas dari bahan baku daun cincau.

3) Pelatihan teknik pengemasan es daun cincau, keripik daun cincau, dan nastar berbahan tepung daun cincau.

Hasil yang diharapkan : 

a. Kemasan es daun cincau yang khas dan menarik
b. Kemasan kerpik daun cincau yang khas dan menarik
c. Kemasan nastar berbahan daun cincau yang khas dan menarik
d. Mitra mampu dan terampil mengemas produk dengan merek dan tampilan yang menarik
4) Pelatihan teknik promosi dan pemasaran produk permen jelly, dodol dan kerupuk dari rumput laut Hasil yang diharapkan :
a. Mitra mempunyai pengetahuan tentang teknik pemasaran produk.
b. Mitra mampu dan terampil dalam memasarkan ketiga produk secara kontinyu
c. Mitra memiliki wawasan dan pengetahuan yang mendalam mengenai kiat-kiat mengelola suatu bisnis/usaha
d. Mitra mampu mengelola usahanya dengan baik.

\section{KESIMPULAN}

Dari analisa perhitungan "Perencanaan dan Pembuatan Konstruksi Alat Pemisah Batang dengan Daun Tanaman Lawsonia Inermis Kapasitas $1 \mathrm{~kg} / \mathrm{jam}$ menggunakan motor bensin" diperoleh kesimpulan sebagai berikut :

1. Terciptanya alat pemisah batang dengan daun tanaman Lawsonia Inermis yang berfungsi dengan baik. Dimensi alat Pemisah batang dengan daun tanaman Lawsonia Inermis memiliki Panjang $1000 \mathrm{~mm}$, lebar $700 \mathrm{~mm}$, dan tinggi $1180 \mathrm{~mm}$. Motor penggerak menggunakan motor bensin.

2. Sebelum proses pemilihan bahan, dilakukan perhitungan terhadap hasil rancangan alat pemisah batang dengan daun tanaman Lawsonia Inermis. Hal ini dilakukan untuk mengetahui kekuatan dari rancangan rangka alat pemisah batang dengan daun tanaman Lawsonia Inermis dan mendapatkan hasil bahwa hasil rancangan tersebut telah layak untuk digunakan.

Di dalam konstruksi alat perontok daun tanaman Lawsonia Inermis terdapat beberapa saran yang harus diperhatikan untuk mendapatkan hasil analisis yang lebih baik, yaitu:

1. Pada penelitian selanjutnya harap diperhatikan pembebanan dan kondisi batas pada konstruksi alat perontok daun tanaman Lawsonia Inermis agar hasil yang di dapat sesuai dengan hasil dilapangan.

2. Menggunakan jenis material yang berbeda.

3. Melakukan perancangan menggunakan perangkat lunak selain Autodesk Inventor Professional 2017 untuk mendapatkan hasil yang lebih optimum.

4. Dalam proses desain dan perhitungan konstruksi rangka alat perontok daun tanaman Lawsonia Inermis ini yang perlu diperhatikan adalah dalam menghitung beban yang diterima oleh rangka dan juga pemilihan bahan yang sesuai dengan kebutuhannya.

Untuk hasil lebih maksimal, perlu adanya penambahan ukuran rangka agar dapat menambah kapasitas pisau perontok yang lebih besar, sehingga dapat emaksimalkan kapasias daun yang rontok yang dihasilkan.

\section{DAFTAR PUSTAKA}

Adi, P. Yanuar, B. Suryadiwansa, H. Perancangan Dan Pembuatan Struktur Mekanik Sistem Inspeksi Visi. Fakultas Teknik, Universitas Lampung.

Ady, S. Rofandi, H. \& Warji. (2014). Rancang Bangun Dan Uji Kinerja Mesin Perontok Biji Jali (Coix Lacryma Jobi L) Tipe Roll Silinder Pejal. Jurnal Teknik Pertanian Lampung

Alchazin, Syaiful, (2011). Modul Training Autodesk Inventor 2012, Lapan, Bogor. 
Ardi, F, Y. (2016). Desain Dan Kinerja Mesin Pemisah Tangkai Dan Daun Teh. Fakultas Teknologi Pertanian, Institut Pertanian Bogor

Harsokoesoemo, Darmawan. (2000). Pengantar Perancangan Teknik (Perancangan Produk). Jakarta: Direktorat Jenderal Pendidikan Tinggi Departemen Pendidikan Nasional.

Hidayat, Nur dkk. Autodesk Inventor Mastering 3D Mechanical Design. Bandung: Informatika, 2011.

Indra, S, Jumari. (2014). Perencanaan Konstruksi Mesin Penggiling dengan Sistem Roda Gigi. Fakultas Teknik, Universitas Muhammadiyah Jakarta

Junior, R, S. (2019). Optimasi Desain Suatu Poros Turbin Air Banki Untuk Pembangkit Listrik Tenaga Mikro Hidro (PLTMH). Fakultas Teknik, Universitas Negeri Jakarta

Juvinall, R, C. (1967). Engineering Considerations Of Stress, Strain, And Strength. Mc Graw Hill, Inc. New York.

Muldiyono, A. Evi, S. Burhan, L. (2019). Rancang Bangun Prototipe Mesin Pengupas Buah Kapuk Dengan Prinsip Pemisah Biji Dan Serat Kapuk Menggunakan Penggerak Motor Bakar. Jurnal Teknologi Pertanian Gorontalo (JTPG)

Popov, E, P. (1996). Mechanis Of Materials. Terjemahan oleh Astamar, Zainul. Jakarta: Erlangga

Robiyansyah. (2015). Perancangan Mesin Pencacah Pelepah Sawit Untuk Pakan Ternak Sapi. Jurusan Teknik Mesin, Universitas Pasir Pengaraian

Setyo, A, P. (2012). Proses Pembuatan Rangka Pada Mesin Penyuir Daging Untuk Bahan Baku Abon. Fakultas Teknik, Universitas Negeri Yogyakarta

Sularso, \& Suga, K. (2004). Dasar Perencanaan Dan Pemilihan Elemen Mesin 352. PT Pradnya Paramita, Jakarta.

Susatio, Yerri. (2004). Dasar-dasar Metode Elemen Hingga. Yogyakarta: Andi Publisher.

Waguespack, Curtis. (2013). Mastering Autodesk Inventor 2014 dan Autodesk Inventor LT 2014, John Wiley \& Sons, Inc. Canada.

Zaqi, N, M. (2018). Analisis Finansial Mesin Pencacah Jerami Yang Di Modifikasi Dari Mesin Perontok Padi. Fakultas Pertanian, Universitas Sriwijaya 